\title{
TEMAS SENSÍVEIS NO ENSINO DE HISTÓRIA: PRODUZINDO CONHECIMENTO HISTÓRICO ESCOLAR NA RELAÇÃO PASSADO/PRESENTE
}

\section{CONTROVERSIAL ISSUES IN HISTORY TEACHING: PRODUCING SCHOOL HISTORICAL KNOWLEDGE IN THE PAST/PRESENT RELATION}

\author{
Thays Merolla Piubel ${ }^{1}$
}

\begin{abstract}
RESUMO
A proposta desse artigo é articular produções teóricas do Ensino de História, entendido em uma dupla dimensão, enquanto campo de pesquisa e como espaço de produção de conhecimento. O objetivo é compreender a produção do conhecimento histórico escolar a partir de temas sensíveis, entendidos aqui enquanto temas que estão historicamente associados ao uso de violência contra grupos marginalizados, gerando um trauma que reverbera no tempo presente, em disputas por saberes e poderes. A ideia é discutir as potencialidades e as tensões do uso desses temas sensíveis no currículo de História no tempo presente, em uma perspectiva de temporalidade não linear entre passado e presente, em um fazer curricular político, produtor de identidades e dos direitos humanos.
\end{abstract}

\section{PALAVRAS-CHAVE}

Ensino de História; Temas sensíveis; Conhecimento histórico escolar; Currículo; Temporalidade.

\begin{abstract}
The purpose of this article is to articulate theoretical productions of History Teaching, understood in a double dimension, as a research field and as a space to produce knowledge. The objective is to understand the production of historical school knowledge based on sensitive themes, understood here as themes that are historically associated with the use of violence against marginalized groups, generating a trauma that reverberates in the present time, in disputes over knowledge and powers. The idea is to discuss the potentialities and tensions of using these controversial issues in the History curriculum in the present time, in a perspective of non-linear temporality between past and present, in a political curriculum making, producer of identities and human rights.
\end{abstract}

\section{KEYWORDS}

History teaching; Controversial issues; School historical knowledge; Curriculum; Temporality.

\footnotetext{
${ }^{1}$ Doutoranda em Educação no Programa de Pós-Graduação em Educação da Universidade Federal do Rio de Janeiro (PPGE/UFRJ). Mestra em Educação e Licenciada em História pela mesma universidade. Especialista em Ensino de História pelo Colégio Pedro II. Professora de História da Prefeitura Municipal de Maricá.
} 


\section{Introdução}

O presente artigo tem por objetivo articular temáticas relevantes e atuais do campo do Ensino de História tais como temporalidade e temas sensíveis de maneira a debater as potencialidades dessas articulações na produção curricular da História, considerando um momento político de disputas discursivas no qual a disciplina tem sido central. Essa discussão se relaciona com a dissertação de mestrado defendida no Programa de PósGraduação em Educação da UFRJ intitulada "Regimes de verdade e temas sensíveis: Currículos e professores de História tensionados nas disputas sobre o racismo",2, sob orientação da Prof. ${ }^{a}$ Dr ${ }^{a}$. Ana Maria Ferreira da Costa Monteiro.

Nos últimos anos, principalmente a partir de meados da década de 2010, têm ganhado cada vez mais força discursos que questionam os saberes científicos, tensionando os saberes produzidos nas universidades e nas escolas, processo que entendemos enquanto uma intensificação das disputas discursivas a partir do fortalecimento de discursos conservadores e de extrema-direita. Esses discursos conservadores e de ódio passaram a questionar os regimes de verdades (FOUCAULT, 2011) contingencialmente estabelecidos pela Academia e pela escola no campo da História acerca do nazismo, do Holocausto, da ditadura civil-militar brasileira, da escravidão negra e indígena e do racismo, em um processo de revisão ou negação desses eventos, diminuindo sua importância histórica e carga traumática.

Os regimes de verdade (FOUCAULT, 2011) se tratam de conjuntos de proposições, instituições e disciplinas que produzem controle e coerção sobre os discursos, sobre o que pode ser enunciado enquanto verdadeiro e falso. Dessa maneira esses regimes fabricam o exercício do poder e a produção de saberes, sendo a normatividade fundamental para sua manutenção, através do processo de controle político dos corpos, a biopolítica. (SOUZA, 2016, p. 8)

No contexto que estamos vivenciando no Brasil, mas não somente, observamos uma amplificação do questionamento do discurso das ciências em produzir a "verdade", discurso esse próprio da modernidade, tensionando a posição do regime de verdade

\footnotetext{
${ }^{2}$ A dissertação pode ser acessada no site do Programa de Pós-Graduação em Educação da UFRJ: https://ppge.educacao.ufrj.br/ppge-dissertacoes-2020.html
} 
hegemônico. Um dos movimentos que observamos enquanto indício da intensificação das disputas em torno dos regimes de verdade na contemporaneidade, em acordo com a reflexão citada abaixo da Rede Brasileira de História Pública, é o do revisionismo produzido no âmbito do senso comum.

\begin{abstract}
Em geral, quem nega o peso do passado são os perpetradores - aqueles a quem a história deve cobrar a conta dos massacres, perseguições, etnocídios e genocídios. Uma história polifônica implica o destrinchamento, e não o apagamento, das formas pelas quais a própria história e a memória se construíram. O próprio revisionismo - enquanto fenômeno contemporâneo global que, no Brasil, tem servido para encobrir a violência e o autoritarismo do nosso passado - deve ser tomado como objeto de análise. Cabe compreender e explicar em que sentido os gestos negacionistas e revisionistas que questionam a história da escravidão ou da ditadura militar brasileira, por exemplo, são também reações violentas e autoritárias contra a democratização da história. (REDE BRASILEIRA DE HISTÓRIA PÚBLICA, 2019, p. 184)
\end{abstract}

Esse processo de amplificação dos discursos revisionistas/negacionistas, a partir de vontades de saber e poder da ordem do autoritarismo e do conservadorismo buscam, em associação com discursos da ordem do religioso, se hegemonizar no seio social. No caso da História essa disputa se intensifica tendo em vista a questão das identidades, das narrativas nacionais em jogo e do processo de democratização na produção e acesso às narrativas históricas. E nesse sentido a dimensão do político é fundamental para compreender a partir de quais vontades de saber e poder tais grupos atuam: quais discursos desejam interditar, quais saberes desejam produzir e quais sujeitos desejam controlar.

No caso da História escolar, essas disputas discursivas têm interferido no trabalho docente, questionando as narrativas históricas dos professores e construindo sentidos negativos sobre determinados grupos de sujeitos históricos, como as populações afrobrasileiras e indígenas. Tais perspectivas costumam confrontar a questão do trauma que esses grupos historicamente marginalizados sofreram e a continuidade de exclusões e violências enfrentadas até os dias de hoje. Por conta dessas disputas e da importância de trabalhar essas temáticas em sala de aula, nos utilizamos do conceito de "temas sensíveis" para tratar dessas questões. Entendemos que esses temas sensíveis têm sido centrais nas disputas discursivas acerca de quais saberes e sujeitos são legitimados nos currículos do ensino de História. 
O Ensino de História, campo disciplinar central na produção desse artigo, está sendo entendido aqui enquanto "lugar de fronteira" (MONTEIRO; PENNA, 2011) entre os campos da História e da Educação, de forma a constituir um referencial teórico complexo para pensar a História ensinada. A fronteira, nessa perspectiva, não é entendida na acepção de limite, e sim de lugar de encontros entre saberes constituídos em campos diversos, porém complementares, negociando distâncias. No espaço desse artigo e em nossas pesquisas temos defendido o campo do Ensino de História enquanto espaço imprescindível nos debates, pesquisas e práticas sobre a História ensinada, sendo, portanto, um espaço político que deve ter o compromisso em se posicionar nessas disputas que, como já mencionado, interferem no trabalho docente tanto na educação básica quanto superior, questionando os saberes e narrativas dos professores.

As contribuições principais no campo da História se referem aos subcampos da Teoria da História e Historiografia, de forma a pensar o conteúdo curricular da disciplina a partir dos fluxos do saber acadêmico, além da importância da temporalidade na constituição desse saber. Já no campo da Educação, os subcampos da Didática e do Currículo contribuem com reflexões sobre os saberes docentes e as práticas curriculares dos professores. Nesse sentido, o campo do Currículo é importante referencial na reflexão acerca do ensino de História ao propor questionamentos acerca de quais saberes, poderes e sujeitos estão produzindo e sendo produzidos pelo currículo. A articulação entre esses dois profícuos campos de pesquisa - o Ensino de História e o Currículo - nos permite ampliar a densidade teórica das reflexões sobre os conhecimentos escolares produzidos sobre os temas sensíveis na disciplina História, no escopo desse artigo.

O artigo está organizado em três seções. Na primeira seção discutimos a relação entre currículo e conhecimento escolar, refletindo acerca das produções que tem se consolidado no campo do Currículo sobre essas temáticas. Na segunda seção conceituamos o que são os temas sensíveis e tecemos considerações a respeito de sua relevância para um ensino de História significativo, desenvolvendo paralelamente uma reflexão sobre a questão do racismo enquanto um exemplo de tema sensível da História do Brasil. Já na terceira seção buscamos articular as dimensões anteriores, debatendo as potencialidades do uso dos temas sensíveis no trabalho com a temporalidade na produção do conhecimento histórico escolar. 


\section{Currículo e produção do conhecimento escolar}

O entendimento de currículo com o qual estamos operando é o de currículo como "espaço-tempo de produção de significados, identidades, diferença, disputa de sentidos sobre os processos e fenômenos do mundo" (MONTEIRO; GABRIEL, 2014, p. 34). A partir dessa perspectiva podemos incluir as questões sensíveis enquanto espaços de disputa por sentidos e significados sobre os conhecimentos legitimados ou subalternizados no âmbito educacional, sendo, portanto, disputa política e cultural nas contingências do poder. Nessa perspectiva, o professor é entendido como um importante produtor de currículo e de conhecimento histórico escolar em sua prática profissional, ainda que esteja constantemente no centro de disputas dentro e fora da escola sobre os sentidos de escola, professor, ensino e conhecimento.

Uma perspectiva relevante dentro do campo do Currículo tem sido a produção teórica acerca da categoria "conhecimento escolar" ou "saber escolar". Essa categoria nos parece potente para pensar uma epistemologia da produção do conhecimento própria do âmbito da escola, ao conferir equivalência entre o conhecimento científico e o conhecimento escolar, sem hierarquizações que desqualificam a produção escolar. Nesse sentido, há o entendimento que essas produções são constituídas de maneiras diferentes, sendo importante considerar possibilidades de diálogo entre elas. No Brasil, esse conceito foi apropriado e ressignificado no trabalho de autoras como Ana Maria Monteiro (2007, 2014), Alice Casemiro Lopes (2007) e Carmen Teresa Gabriel (2014).

Ana Maria Monteiro (2007), partindo das contribuições dos franceses Yves Chevalard e Michel Develay vai operar com o conceito de "transposição didática" com o objetivo de compreender a produção do conhecimento histórico escolar e dos saberes docentes. Segundo a autora, esse conhecimento escolar, produzido na transformação do saber acadêmico em saber a ser ensinado (Chevalard) não se limita apenas ao fluxo de cientificidade. Tal conhecimento se constitui também a partir das práticas sociais de referências (Develay): dentre elas podemos citar as referências culturais, as vivências dos estudantes, as práticas sociais e as pesquisas. Nessa perspectiva, além do caráter didático dessa prática, se incorporam também valores a esses saberes, o que a autora considera fundamental no ensino de História. 
Alice Casemiro Lopes (2007) vai investir teoricamente em estabelecer relações entre conhecimento científico e conhecimento escolar, entendendo tais conhecimentos como práticas sociais contingenciais. Para a autora, o conhecimento escolar é produzido socialmente para finalidades específicas de escolarização, em processos de seleção e organização de conteúdo a partir de relações de poder. A autora não se preocupa com a primazia do fluxo de cientificidade no conhecimento escolar, pois entende que tal perspectiva assume um viés cientificista que ignora a própria contingência da produção científica, defendendo, portanto, a legitimidade da cultura escolar em produzir saberes próprios.

Carmen Teresa Gabriel, juntamente com Luciene Moraes (2014) visa articular os conceitos de conhecimento escolar e conteúdo, buscando compreender quais os sentidos hegemônicos que são fixados desses termos nas políticas curriculares, entendendo que os termos não são sinônimos, mas são apropriados como tal para satisfazer determinadas demandas. Segundo as autoras, quando os termos são posicionados como equivalentes, o conhecimento escolar é legitimado frente às demandas sociais, pois tem no "conteúdo" seu fluxo de cientificidade "garantido". As autoras procuram afirmar o conhecimento escolar enquanto luta política.

Gabriel e Monteiro (2014, p. 33-34) vão defender a categoria de "conhecimento escolar", reconhecendo a potencialidade da dimensão educativa ser estruturante nesse processo de constituição e a necessária interação com o conhecimento científico. Nesse sentido, o reconhecimento do diálogo constante com os fluxos da cientificidade não implica em negar a perspectiva cultural e contingente da produção científica, realizada em determinada temporalidade por determinados sujeitos a partir de regimes de verdade e, portanto, parciais. No entanto atestam a fertilidade desse diálogo, postulando uma equivalência epistemológica e consequente valorização da produção curricular no âmbito da escola e do sujeito docente, ainda que reconheça as relações de poder desiguais entre essas dimensões de produção.

As problematizações acerca do conhecimento escolar reconhecem que a questão sobre qual conhecimento deve ser ensinado nas escolas é central, tendo em vista que a legitimação de determinados conhecimentos, usualmente o conhecimento científico disciplinarizado, produz exclusões de diversas ordens. Ao considerar que o currículo é seleção e organização de conhecimentos para fins educacionais e que, portanto, engendra 
relações de poder, também problematizamos o papel marginalizado reservado aos professores nessa produção, que muitas vezes são apresentados a um currículo pronto, e apostamos na importância da figura do professor nesse processo de transformação curricular.

Portanto, considerando as perspectivas e as teorizações apresentadas nessa seção, entendemos que o conhecimento escolar se constitui enquanto uma aposta no fazer curricular no âmbito escolar e no papel do professor enquanto mediador nesse processo. Acreditamos que o conhecimento escolar pode viabilizar a construção de espaços educativos mais democráticos e menos excludentes, possibilitando processos de subjetivação, qualificação e socialização significativos.

\title{
Temas sensíveis: as marcas do passado no tempo presente
}

Os temas sensíveis ou controversos (PEREIRA; SEFFNER, 2018; GIL; EUGENIO, 2018) estão diretamente relacionadas à questão do "trauma", ou seja, processos históricos que engendraram violência física e/ou simbólica contra grupos sociais e que permanecem enquanto passados vivos, que não passam, e reverberam no tempo presente, gerando incômodo, disputa e controvérsia dentro e fora das salas de aula. Segundo Gil e Eugenio:

\begin{abstract}
No Brasil, alguns temas sensíveis seguem na esteira das lutas de diferentes grupos em busca de legitimidade para suas histórias e memórias, questionando a homogeneização que marca a ideia de nação. Junto a isso, os grupos buscam ampliar a representação política, e a luta por direitos faz emergir demandas identitárias. Ou seja, é uma luta que reivindica lembrar, manter viva uma memória e reparar o silêncio e as simplificações na narrativa histórica. Assim, a unidade nacional tem sido questionada - não sem resistência - dando visibilidade à uma sociedade que é multicultural. Tal fenômeno tem provocado debates sobre o currículo da História ensinada de forma que possa construir materiais didáticos, rituais comemorativos e práticas curriculares na perspectiva da justiça e dos direitos humanos. (GIL; EUGENIO, 2018, p. 143)
\end{abstract}

Nesse sentido, o ensino de História é espaço privilegiado nas disputas acerca das histórias e memórias sobre os temas sensíveis, tendo em vista as tensões nas produções curriculares na disciplina: há uma crítica à permanência de um currículo eurocêntrico, linear, colonizado e também há a emergência de um currículo multicultural, processual e descolonizado, gerando um embate político e discursivo sobre o que deve ser ensinado 
na disciplina História, sobre quais sujeitos devem ter suas histórias narradas, representadas e celebradas e sobre quais histórias devem ser esquecidas, marginalizadas e subalternizadas. Nessa perspectiva, nos parece que as legislações que instituíram a obrigatoriedade do ensino da história dos africanos, afro-brasileiros e indígenas, a partir da Lei 10.639/03 e Lei $11.645 / 08^{3}$ ampliaram as tensões nesse embate ao inserir sujeitos marginalizados de forma prescritiva nos currículos de História.

No bojo dessa discussão, vamos desenvolver uma reflexão acerca do racismo enquanto tema sensível da/na História do Brasil, apresentando um breve histórico sobre a questão e de que maneira reverbera nas salas de aula e nas disputas políticas, tensionando-as. O debate teórico em torno das questões étnico-raciais é de extrema relevância para o ensino de História, especialmente os conceitos de raça e etnia, mas também os processos históricos relacionados à escravidão, que deixaram marcas indeléveis na sociedade brasileira, pois apesar de ter ocorrido no final do século XIX o fim da escravidão formal, o racismo perdura até os dias de hoje, de forma velada e explícita, no cotidiano, nas práticas e nas instituições.

Segundo Hall (2009, p. 66), “'Raça' é uma construção política e social. É a categoria discursiva em torno da qual se organiza um sistema de poder socioeconômico, de exploração e exclusão - ou seja, o racismo.” O conceito de raça, em sua acepção primeira enquanto um determinante biológico de características físicas e comportamentais foi elaborado de forma a fundamentar o racismo científico e o colonialismo no século XIX e reverbera até os dias de hoje. A raça é um dos conceitos estruturantes da modernidade, juntamente com a colonialidade, os quais geraram e permanecem gerando formas perversas de marginalização e exclusão de sujeitos e saberes externos ao mundo eurocentrado.

No Brasil, na segunda metade do século XIX, a perspectiva eugenista, que visava um melhoramento das características físicas e mentais de uma população amparada no racismo científico vai estimular práticas de embranquecimento da população brasileira, por exemplo, fornecendo subsídios públicos para a vinda de imigrantes europeus e proibindo a imigração de povos africanos. Reconhecendo a impossibilidade desse projeto, ao longo do século XX a ideia de mestiçagem vai ser positivada, entendida enquanto

\footnotetext{
${ }^{3}$ A Lei 11.645/08 dispõe sobre a obrigatoriedade do ensino de história e cultura africana, afro-brasileira e indígena na educação básica, especialmente nas disciplinas História, Literatura e Educação Artística.
} 
contribuições das diversas raças na formação do povo brasileiro, em trabalhos de intelectuais como Gilberto Freyre, por exemplo. Esse discurso ainda reverbera e possibilita o apagamento do racismo através do mito da democracia racial, segundo o qual, no Brasil, por ser um país profundamente miscigenado, haveria uma convivência pacífica e não racista entre as pessoas, gerando um mecanismo perverso de negacionismo do racismo na sociedade brasileira.

Já no final do século XX, a Constituição Federal do Brasil de 1988 prevê em seus artigos $1^{\circ}$ e $5^{\circ}$ o repúdio ao racismo, considerando-o enquanto crime inafiançável e imprescritível. Esse intento antirracista foi intensificado na década de 2000 através de legislações, materiais didáticos, fomento de ações culturais e educativas, salvaguarda de bens culturais, cotas de acesso a universidades públicas, dentre outros, de maneira a tensionar, mesmo que sutilmente, o racismo estrutural e institucional arraigado no país.

Contudo, a partir da década de 2010 temos assistido à amplificação de discursos conservadores e o recrudescimento da extrema-direita em todo o mundo, e no Brasil não tem sido diferente. Nesse contexto tem ocorrido um aumento na circulação de discursos revisionistas e negacionistas acerca dos saberes produzidos nas universidades e nas escolas, como os movimentos antivacina e terraplanista e no caso da História a negação do Holocausto, o nazismo ter sido um movimento de extrema-esquerda e no caso da história do Brasil a negação da ditadura civil-militar brasileira e da escravidão, inclusive com discursos negacionistas à nível institucional do governo do Brasil ${ }^{4}$.

A educação tem sido arena de embates entre grupos conservadores e progressistas sobre quais saberes e sujeitos são legítimos e legitimados a estarem representados nos currículos de História e sobre o que o professor pode ensinar. Movimentos como o Escola

\footnotetext{
${ }^{4}$ Apenas para citar um dos inúmeros exemplos ocorridos ao longo do primeiro ano do governo do presidente Jair Bolsonaro, o jornalista Sérgio Nascimento de Camargo, nomeado para ocupar a presidência da Fundação Cultural Palmares, em suas redes sociais publicou postagens com mensagens como: "A escravidão foi terrível, mas benéfica para os descendentes"; "Racismo real existe nos Estados Unidos. A negrada daqui reclama porque é imbecil e desinformada pela esquerda" e sobre o Dia da Consciência Negra, que "causa incalculáveis perdas à economia do país, em nome de um falso herói dos negros (Zumbi dos Palmares, que escravizava negros) e de uma agenda política que alimenta o revanchismo histórico e doutrina o negro no vitimismo". Esse discurso se opõe frontalmente ao objetivo institucional da Fundação de "combate ao racismo, a promoção da igualdade, a valorização, difusão e preservação da cultura negra" (site institucional), com possibilidade de esvaziamento institucional, gerando forte oposição social que resultou na suspensão da nomeação. Fonte: Após decisão da Justiça, governo suspende nomeação do presidente da Fundação Palmares. G1 Política, 12 dez. 2019. Disponível em: <https://g1.globo.com/politica/noticia/2019/12/12/governo-suspende-nomeacoes-dos-presidentes-dafundacao-palmares-e-iphan.ghtml >. Acesso em 20 jan. 2020.
} 
sem Partido procuram tolher a liberdade de cátedra e de pluralismo de ideias e concepções pedagógicas dos professores, assegurados pela Constituição brasileira de $1988^{5}$.

Acerca do trabalho com os temas sensíveis em sala de aula e especificamente com o racismo, não é possível trabalhar apenas em uma perspectiva. É necessário que o passado vivo e as emoções sejam constituintes na produção desse conhecimento histórico escolar. O passado vivo deve se fazer presente na medida que implica pensar nas questões sensíveis, na temporalidade e na diferença. Os temas sensíveis têm por horizonte desestruturar uma temporalidade linear, o que será explorado na próxima seção, e produzir histórias outras, partindo de outros sujeitos anteriormente marginalizados. E de forma a trabalhar com processos históricos permeados pela violência, o mesmo deve ser capaz de provocar sensações, como nos dizem Seffner e Pereira:

O que se precisa pensar é justamente a ideia de que aprender sobre o genocídio indígena no Brasil não pode ser algo que o professor simplesmente exponha em aula, como "matéria dada". Há que se ter acontecimento nessa aula: que alguém chore, que alguém se espante, que alguém ache um absurdo, que alguém diga "professor, o senhor não tem o direito de nos mostrar isso que está nos mostrando! O senhor não tem o direito, é muito forte, é muito pesado!". Uma aula de história provoca sensações, muito mais que simplesmente ensina causas, efeitos e consequências. (SEFFNER; PEREIRA, 2018, p. 23)

No caso do racismo é fundamental estabelecer relações e traçar paralelos entre as vivências da população escravizada negra entre os séculos XVI e XIX no Brasil e no mundo, e na contemporaneidade. Isso inclui falar do genocídio da população negra jovem, das condições socioeconômicas, da falta de acesso às oportunidades educacionais e de empregos bem remunerados, do racismo estrutural e institucional. Ou seja, não basta apenas apresentar fontes textuais, fontes imagéticas e dados estatísticos. Contudo, isso não deve significar a ausência de fluxos do conhecimento científico e acadêmico, pois como discutido na seção anterior, este é um dos fluxos que compõem esse saber complexo que é o saber escolar.

Em um contexto tão desafiador quanto o que estamos vivenciando enquanto professores preocupados com a formação ética de nossos estudantes, é fundamental nos apropriarmos dos instrumentos legais que nos possibilitam a liberdade de escolha, que

\footnotetext{
${ }^{5}$ Para mais informações sobre a atuação do Escola sem Partido e de que maneira os professores estão o combatendo, acesse: <https://profscontraoesp.org/. Acesso 10 mar. 2020.
} 
segundo Mével e Tutiaux-Guillon (2013 apud GIL; EUGENIO, 2018, p. 142) é a liberdade própria do professor e que são sempre escolhas políticas. Dentre esses instrumentos legais podemos citar a Lei $10.639 / 03$ e a Lei $11.645 / 08$, anteriormente referenciadas, as Diretrizes Curriculares Nacionais para a Educação das Relações ÉtnicoRaciais e para o Ensino de História e Cultura Afro-Brasileira e Africana (2004), o Plano Nacional de Educação em Direitos Humanos (2006) e as Diretrizes Nacionais da Educação em Direitos Humanos (2013).

Portanto, considerando o que foi debatido nessa seção, entendemos que os temas sensíveis ou controversos são importantes na produção de conhecimento no ensino de História, não apenas em uma dimensão de conhecimento disciplinar, mas também na dimensão produtora de identidades plurais, ressignificando o passado no tempo presente, de pensar leituras e possibilidades outras de mundo e de uma postura ética e política frente às violações dos direitos humanos.

\section{Os temas sensíveis e a produção do conhecimento histórico escolar na relação com a temporalidade}

Nos apropriamos de contribuições da História para pensar a questão da temporalidade, especificamente as discussões em torno da história do tempo presente (DELGADO; FERREIRA, 2013; ROUSSO, 2016), dimensão fundamental para compreender os temas sensíveis, tendo em vista que esses temas são entendidos enquanto questões do tempo presente. Contudo, não há uma definição única do que seja a história do tempo presente, sendo um campo de pesquisa em processo de consolidação na História acadêmica.

Dentre as definições possíveis estão história com "presença de testemunho vivos", "período posterior à uma última grande ruptura", "época em que vivemos", dentre outras (DELGADO; FERREIRA, 2013, p. 22-23). Contudo, essas definiçõos de história do tempo presente não dão conta da questão da escravidão, tendo em vista o fim legal da mesma ter ocorrido há 130 anos e entendida enquanto responsável direta pelo racismo vivenciado atualmente pelas populações negras. 
Se considerarmos uma definição de história do tempo presente conforme Rousso, citada abaixo, podemos compreender o racismo enquanto remanescente da escravidão no tempo presente.

“(...) uma maneira de fazer, um modo de pensar a história quando esta atinge, ou mesmo ultrapassa, o limite do compreensível e do aceitável. Ela se acha em todo lugar que o passado deixou marcas a ferro quente nos corpos, nos espíritos, nos territórios, nos objetos" (ROUSSO, 2016, p. 19)

Para nossa reflexão, articulada ao ensino de História, é importante distinguir a história do tempo presente e o presentismo enquanto regime de historicidade, sendo este uma forma de dar sentido ao tempo, de indagar sobre as diferentes "maneiras de ser no tempo" (HARTOG, 2014, p. 29). A história do tempo presente, enquanto campo de pesquisa sobre a História, se trata de investigar os acontecimentos recentes da História, principalmente após o contexto do pós-Segunda Guerra Mundial, se contrapondo a uma perspectiva tradicional que defende a necessidade de um distanciamento temporal para a produção historiográfica.

Já o presentismo se trata de um regime de compreensão do tempo no qual apenas o "aqui e agora" importa, apagando as dimensões de passado e futuro, em um "presente perpétuo", em que "tudo se passa como se não houvesse nada mais que o presente" (HARTOG, 2014, p. 39-40). É digna de nota a percepção de que cada vez mais o discurso dos estudantes da educação básica tem sido enunciado a partir do presentismo em relação à disciplina História, questionando qual o sentido para o estudo do passado.

O Ensino de História, a partir dessas contribuições da Teoria da História na reflexão sobre a questão da temporalidade, central para o estudo, pesquisa e ensino da História, vai produzir novas possibilidades de se pensar a temporalidade ao desestruturar a temporalidade cronológica linear eurocêntrica.

O professor Diego Bruno Velasco, em pesquisa realizada a partir de entrevista com professores de História que atuam nas escolas públicas de educação básica na cidade do Rio de Janeiro, propôs um exercício de análise com o objetivo de compreender os desafios e as potencialidades da articulação entre passado e presente nas aulas de História na produção do conhecimento histórico escolar. $\mathrm{O}$ autor partiu das seguintes questões nas entrevistas para produzir suas reflexões: “Quais são os desafios atuais que os professores 
de História enfrentam para trabalhar esta disciplina?" e "Quais conteúdos históricos você destacaria como sendo indispensáveis para se articular ou com a realidade dos alunos ou com a formação do cidadão crítico?” (VELASCO, 2017, p. 133)

Acerca dos resultados das entrevistas, o autor nos diz:

Em termos de considerações finais, destaco, portanto, que as entrevistas analisadas me permitem visualizar que conceitos como "Democracia", "Cidadania", "Preconceitos", "Discriminações", "Relações de Trabalho" principalmente quando se encontram articulados a temas da História do Brasil como Escravidão e Ditadura ou da História Geral como "Democracia Ateniense" e "Revolução Industrial" ocupam, provisoriamente, a cadeia definidora do que é um "ensino de História de qualidade" em que é importante articular o saber histórico escolar com o que tradicionalmente é denominado de 'realidade do aluno'. (VELASCO, 2017, p. 150)

É interessante notar que os temas e conceitos mencionados acima pelos professores de História da educação básica se relacionam diretamente com as questões sensíveis (preconceitos e discriminações) e os direitos humanos (cidadania e democracia) sobre os quais falamos anteriormente. Isso demonstra que um "ensino de História de qualidade" para esses professores e para seus estudantes se dá quando questões do passado vivo se fazem presentes nas aulas.

Para pensar os temas sensíveis enquanto passados vivos, os professores Nilton Mullet Pereira e Fernando Seffner desenvolvem reflexões a partir de apropriações dos conceitos de remanescência e residualidade, que desestruturam a temporalidade linear ao estabelecer conexões diretas, porém diversas entre passado e presente.

Dessa forma, temos um passado vivo que se prende ao presente como residualidade ou como remanescência, constituindo o ser do paradoxo temporal. As aulas de história se põem a tomar como conteúdo de ensino e aprendizagem as residualidades do passado que não passam, que se estendem ao presente e que habitam a memória, constituindo experiências. (SEFFNER; PEREIRA, 2018, p. 24)

Os autores utilizam esses termos em detrimento do conceito de permanência, pois entendem que este fixa uma ideia de rigidez e inalterabilidade, o qual não coaduna com a ideia de passado vivo, tendo em vista que tais resíduos do passado não são cópias idênticas em outra temporalidade. Esses remanescentes se atualizam no presente, sem deixar de 
estar atrelado ao passado, insistindo em se manter vivos e produzir sentidos, movimentos, identidades, representações em outra temporalidade.

Nessa seção procuramos evidenciar algumas articulações entre Teoria da História, Ensino de História, temporalidade e temas sensíveis de forma a evidenciar a centralidade da temporalidade na construção do conhecimento histórico escolar e o necessário tensionamento de uma temporalidade linear em prol da vivacidade do tempo presente no ensino de História.

\section{Considerações Finais}

O artigo buscou apresentar algumas considerações de ordem teórica acerca da produção do conhecimento histórico escolar e do currículo de História com enfoque na questão dos temas sensíveis e da temporalidade a partir de referenciais teóricos do campo do Ensino de História e das contribuições do campo do Currículo. Em nosso entendimento a articulação desses referenciais nos permite aprofundar a densidade da análise teórica para refletir acerca da História ensinada, suas demandas e desafios no tempo presente.

Buscamos defender ao longo do texto a potencialidade dos temas sensíveis no ensino de História de maneira a realizar o enfrentamento de um contexto de intensificação de disputas discursivas dentro e fora das escolas, que questionam o conhecimento científico e os saberes dos professores. Nesse sentido, entendemos que umas das chaves no posicionamento de professores de História seria a produção de um conhecimento histórico escolar plural, que tenha em conta as demandas do tempo presente, as identidades, o político, a controvérsia, a sensibilidade e o diálogo.

A produção de conhecimento histórico escolar tendo em conta os temas sensíveis ou controversos, em nosso entendimento, tem a potencialidade em produzir um ensino de História significativo para professores e estudantes. Conforme discutido no decorrer do artigo, esses temas podem contribuir na ruptura com uma temporalidade linear e com o eurocentrismo, na medida que dialogam com os traumas e o dever de memória de grupos historicamente marginalizados, que reivindicam ter suas memórias e histórias contadas e valorizadas, sendo, portanto, uma demanda política. No âmbito da escola esse movimento pode ser exemplificado a partir da promulgação da Lei 11.645/08, 
que instituiu o ensino da história e cultura africana, afro-brasileira e indígena, tensionando a primazia das culturas e sujeitos eurocêntricos no currículo.

Consideramos que os temas sensíveis possibilitam novas abordagens teóricas, temáticas, metodológicas e epistemológicas para pensar e vivenciar o ensino de História de maneira a desestabilizar concepções hegemônicas acerca de quais sujeitos, saberes e temporalidades são legitimados no currículo de História. Tal abordagem provoca um tensionamento no ensino de História tradicional, abrindo alas para o que o samba enredo da G.R.E.S. Mangueira ${ }^{6}$, campeã do Carnaval do Rio de Janeiro em 2019, nos instiga:

\author{
Brasil, meu nego \\ Deixa eu te contar \\ A história que a história não conta \\ $\mathrm{O}$ avesso do mesmo lugar \\ Na luta é que a gente se encontra \\ Brasil, meu dengo \\ A Mangueira chegou \\ Com versos que o livro apagou \\ Desde 1500 tem mais invasão do que descobrimento \\ Tem sangue retinto pisado \\ Atrás do herói emoldurado \\ Mulheres, tamoios, mulatos \\ Eu quero um país que não está no retrato
}

\title{
REFERÊNCIAS
}

BRASIL. Constituição da República Federativa do Brasil: promulgada em 08 de outubro de 1988. Brasília: Presidência da República, 2019. Disponível em: <http://www.planalto.gov.br/ccivil_03/constituicao/constituicao.htm>. Acesso em 10 fev. 2020.

BRASIL. Lei no 11.645: promulgada em 10 de março de 2008. Brasília: Presidência da República, 2008. Disponível em: <http://www.planalto.gov.br/ccivil_03/_Ato20072010/2008/Lei/L11645.htm>. Acesso em 12 fev. 2020.

DELGADO, Lucilia de Almeida Neves; FERREIRA, Marieta de Moraes. História do tempo presente e ensino de História. História Hoje, v. 2, n. 4, p. 19-34, 2013. Disponível em: <https://rhhj.anpuh.org/RHHJ/article/view/90>. Acesso em 20 fev. 2019.

\footnotetext{
${ }^{6}$ História para ninar gente grande - Samba Enredo 2019, Grupo Recreativo Escola de Samba Estação Primeira de Mangueira. Letra completa disponível em: <https:/www.letras.mus.br/mangueira-rj/sambaenredo-2019-historias-para-ninar-gente-grande/>.
} 
FOUCAULT, Michel. Do governo dos vivos: Curso no Collège de France, 1979-1980: excertos. 2 ed. São Paulo: Centro de Cultura Social; Rio de Janeiro: Achiamé, 2011. 186 p.

GABRIEL, Carmen Teresa; MONTEIRO, Ana Maria Ferreira da Costa. Currículo de História e narrativa: desafios epistemológicos e apostas políticas. In: MONTEIRO, Ana Maria Ferreira da Costa; GABRIEL, Carmen Teresa.; ARAUJO, Cinthia Monteiro;

COSTA, Warley da. (Orgs.). Pesquisa em Ensino de História: entre desafios epistemológicos e apostas políticas. Rio de Janeiro: Mauad X/FAPERJ, 2014. p. 23-40.

GABRIEL, Carmen Teresa; MORAES, Luciene Maciel Stumbo. Conhecimento escolar e conteúdo: possibilidades de articulação nas tramas da didatização. In: . (Orgs.) Currículo e conhecimento: diferentes perspectivas teóricas e abordagens metodológicas. Petrópolis, RJ: De Petrus: FAPERJ, 2014. p. 23-42.

GIL, Carmen Zeli de Vargas; EUGENIO, Jonas Camargo. Ensino de História e temas sensíveis: abordagens teórico-metodológicas. Revista História Hoje, v. 7, n. 13, p. 139159, 2018. Disponível em: <https://rhhj.anpuh.org/RHHJ/article/view/430/273> Acesso em 28 fev. 2019.

LOPES, Alice Casimiro. Conhecimento escolar e conhecimento científico: diferentes finalidades, diferentes configurações. In: Currículo e Epistemologia. Ijuí: Editora UNIJUÍ, 2007. p. 187-204.

LOPES, Alice Casimiro; MACEDO, Elizabeth. "Conhecimento"; "Conhecimento escolar e discurso pedagógico". In: . Teorias de Currículo. São Paulo: Cortez, 2011. Apoio: FAPERJ. p. 70-93; p. 94-106.

HALL, Stuart. Da diáspora: identidades e mediações culturais. Belo Horizonte: Editora UFMG, 2009. 410 p.

HARTOG. François. Regimes de historicidade: presentismo e experiências do tempo. Belo Horizonte: Autêntica Editora, 2014. 272 p. (Coleção História e Historiografia)

MONTEIRO, Ana Maria Ferreira da Costa. Professores de História: entre saberes e práticas. Rio de Janeiro: Mauad, 2007. 262 p.

Ana Maria Ferreira da Costa; PENNA, Fernando de Araujo. Ensino de História: saberes em lugar de fronteira. Educação \& Realidade, Porto Alegre, v. 36, n. 1, p. 191-211, jan./abr. 2011. Disponível em: <https://seer.ufrgs.br/educacaoerealidade/article/download/15080/11518>. Acesso em 23 fev. 2019.

PEREIRA, Nilton Mullet; SEFFNER, Fernando. Ensino de História: passados vivos e educação em questões sensíveis. Revista História Hoje, v. 7, n. 13, p. 14-33, 2018. 
Disponível em: <https://rhhj.anpuh.org/RHHJ/article/view/427/275> Acesso em 28 fev. 2019.

PIUBEL, Thays Merolla. Regimes de verdade e temas sensíveis: currículos e professores de história tensionados nas disputas sobre o racismo. $120 \mathrm{f}$. Rio de Janeiro, 2020. Dissertação (Mestrado em Educação) - Faculdade de Educação, Universidade Federal do Rio de Janeiro, Rio de Janeiro, 2020.

REDE BRASILEIRA DE HISTÓRIA PÚBLICA. Muito além da escola: as disputas em torno do passado no debate público. In: CÁSSIO, Fernando (Org.). Educação contra a barbárie. São Paulo: Boitempo, 2019. p.181-186.

ROUSSO, Henry. A última catástrofe: a história, o presente, o contemporâneo. Rio de Janeiro, FGV Editora, 2016. 344 p.

SOUZA, Joelmar Fernando Cordeiro de. Regimes de verdade em Michel Foucault: aparição e gênese de um conceito. 2016. 112 f. Dissertação (Mestrado em Filosofia) Universidade de Brasília, Brasília, 2016. Disponível em: <https://repositorio.unb.br/bitstream/10482/21055/1/2016_JoelmarFernandoCordeirode Souza.pdf>. Acesso 02 fev. 2020.

VELASCO, Diego Bruno. As articulações entre passado e presente no currículo de História: Desafios e estratégias nos discursos dos professores. Educação Básica Revista, v. 3, n. 2, 2017, p. 131-152. Disponível em: <http://www.laplageemrevista.ufscar.br/index.php/REB/article/view/292/535>. Acesso em 09 fev. 2019. 